\title{
THE FIRST AMENDMENT
}

DANIEL A. FARBER

CAROLINA ZENHA SARAIVA ${ }^{1}$

\begin{abstract}
RESUMO: A presente resenha crítica analisa a obra The First Amendment do autor Daniel A. Farber. Inicia uma análise sobre a historicidade da primeira emenda constitucional norte-americana, enumerando os vários momentos históricos em que a liberdade de expressão e imprensa se fortaleceu e se elevou ao status constitucional. Passa então, ao estudo dos diversos tipos de discursos, iniciando pelo discurso relacionado à emenda constitucional sobre a escravatura, passando pela liberdade de imprensa, liberdade publicitária, discurso de raiva, discurso de preconceito, sempre analisando o posicionamento da Suprema Corte Americana e o papel do Judiciário na formação da Primeira Emenda. Finaliza-se o estudo percebendo a grande polêmica acerca da aplicação da primeira Emenda pelo Judiciário norte-americano, sendo campo importante de pesquisa ao jurista.

PLAVRAS-CHAVE: Liberdade de Expressão; Constituição Norte-Americana; Aplicação da Primeira Emenda; Suprema Corte dos Estados Unidos; Discurso e suas Diversas Espécies.
\end{abstract}

ABSTRACT: This critically review analyzes of the book The First Amendment of Daniel A. Farber. Starts an analysis of the historicity of the First Amendment U.S., listing the various historical moments in which freedom of speech and press has strengthened and elevated to constitutional status. Then proceeds to the study of various types of speeches, starting with the relation of first amendment and slavery, through the freedom of press, freedom of advertising, angry speech, always analyzing the position of the U.S. Supreme Court and the role of judiciary in the evolution of the First Amendment. Terminate the study realizing the great controversy about the implementation of the first amendment by U.S. courts, and important field of research to the law's scientist.

KEYWORDS: Freedom of Speech; The U.S. Constitution; Implementation of the First Amendment; Supreme Court of the United States; Speech and its Diverse Species.

SUMÁRIO: Introdução; 1. Liberdade de Expressão e a Constituição; 2. A Definição da Liberdade de Expressão e sua Aplicação; 3. Matérias Especiais no Contexto da Liberdade de Expressão; 4. A Liberdade de Expressão e a Liberdade Religiosa; Considerações Finais; Referências Bibliográficas.

Resenha recebida em 13.10.2011. Resenha aceita para publicação em 20.12.2011.

${ }_{1}$ Advogada nas áreas de Direito Empresarial e Contencioso Cível, Professora de Direito Empresarial e Processo Civil na Universidade Luterana do Brasil - Ulbra, Campi Canoas e Gravataí, Especialista em Direito Civil pela Uniritter Canoas e Mestranda em Direito no Programa de Pós-Graduação Strictu Senso da Pontifícia Universidade Católica do Rio Grande do Sul. carolina.saraiva@acad.pucrs.br 


\section{INTRODUÇÃO}

$\mathrm{O}$ estudo da Primeira Emenda à Constituição norte-americana é feito através, inicialmente, do estudo de sua evolução ao longo da história dos Estados Unidos, passando pelas guerras civil e mundial experimentadas pela nação estadunidense ${ }^{2}$.

Também necessária a análise dos conteúdos de discurso que estão abrangidos pela proteção constitucional, assim como os locais, as formas e os sujeitos que proferem o discurso.

O exame da evolução jurisprudencial também se faz necessário, uma vez que houve amplificação significativa da aplicação da liberdade de expressão, passando á análise de eficácia frente ao direito de imprensa, de informação, de associação e até mesmo de religião.

A matéria é de extrema importância e relevo pra o entendimento do estudo do direito constitucional norte-americano ${ }^{3}$.

\section{LIBERDADE DE EXPRESSÃO E A CONSTITUIÇÃO}

Para que seja iniciada a análise da Primeira Emenda Constitucional norte-americana, que trata da liberdade de expressão e liberdade de discurso e imprensa, importante analisar a relação da liberdade de expressão e a Constituição.

A Constituição, quando fala da liberdade de expressão, possui texto muito simples, afirmando somente que o Congresso não fará leis que restrinjam a liberdade de discurso, expressão e a liberdade de imprensa ${ }^{4}$.

Apesar da simplicidade do texto empregado para a inclusão da liberdade de expressão no corpo constitucional norte-americano, a evolução do direito de liberdade de expressão no ordenamento norte-americano, através do estudo da jurisprudência e da própria doutrina, mostra que inicialmente a Primeira Emenda restou dirigida somente ao Congresso, passando posteriormente a limitar os poderes do Presidente e das Cortes Federais de Justiça alcançando, no século XXI, também o âmbito dos governos estaduais, cortes e legislação (inclusive constituições) estaduais. Atualmente, em qualquer instância do Judiciário, assim como na elaboração da legislação estatal ou mesmo da atuação da administração pública como um todo ${ }^{5}$.

\footnotetext{
${ }^{2}$ FARBER, Daniel A. The First Amendment. New York: Thomson Reuters, 2010, p. 01-04.

${ }^{3}$ FARBER, 2010, p. 04.

${ }^{4}$ Ibidem, p. 01

${ }^{5}$ Ibidem, p. 06.
} 
A liberdade de expressão, além de ter sua aplicação ampliada frente ao Estado, ao longo do tempo também sofreu aumento quanto à significação do conceito de discurso, de expressão e de imprensa. Tal realidade mostra-se tão latente que, atualmente, a Primeira Emenda permite, inclusive, a possibilidade de queimar uma bandeira em protesto. Não somente as palavras e textos estão, hoje, protegidos pela Primeira Emenda, mas também os atos, mesmo os mais radicais (exemplo já referido de queimar bandeira ou mesmo um crucifixo como forma de liberdade de expressão) ${ }^{6}$.

Assim como nos países democráticos em torno do mundo, os Estados Unidos da América vêm evoluindo quanto à aplicação do direito de liberdade de expressão, sendo atualmente mais determinante a atuação da Suprema Corte do que o próprio texto constitucional propriamente dito, sendo imprescindível estudar a evolução jurisprudencial da aplicação da Primeira Emenda nas cortes superiores, frente à nítida ampliação que foi dada aos conceitos e proteções que englobam tal texto legal.

\subsection{Por que proteger o Discurso e a Liberdade de Expressão}

Para que seja possível o exame da importância da liberdade de expressão num Estado Democrático de Direito, principalmente em um ordenamento jurídico da Common Law como o norte-americano, imprescindível a análise de exemplos de decisões da Suprema Corte nacional, nas quais a proteção pela liberdade de expressão, em muitos casos, choca-se com outros fatores importantes como a moral e o patriotismo.

Um exemplo forte de choque de direitos e até mesmo de liberdade de expressão e moral é o caso Texas v. Johnson ${ }^{7}$, no qual Johnson queimou uma bandeira dos Estados Unidos da América em protesto. Houve grande discussão sobre a possibilidade de alguém, mesmo com o intuito de protesto, poder queimar um símbolo tão importante como a bandeira de uma nação, ato que traz repúdio de boa parte da população.

Outro caso diz respeito à queimada de uma cruz, tendo o ato ocorrido em protesto de estudantes, em movimento inclusive de ideologia racista ${ }^{8}$. Nos dois casos, importante questionar a razão da liberdade de expressão preponderar.

Por que, então, em nome da liberdade de expressão, tolera-se inclusive afirmação falsa e racista, ou que fira a moral ou o patriotismo? Duas são as hipóteses levantadas pela jurisprudência constitucional para que haja essa opção pela proteção quase que absoluta da liberdade de expressão:

a) A primeira hipótese é chamada de auto-realização ou busca pela verdade ${ }^{9}$. A realização pessoal resta relacionada com a liberdade de

\footnotetext{
${ }^{6}$ Ibidem, p. 02-03.

${ }^{7}$ FARBER, 2010, p. 04-06

${ }^{8}$ Ibidem, p. 03.

${ }^{9}$ Ibidem, p. 03-05.
} 
expressão, pois, somente com acesso à informação e liberdade para fazer escolhas e assumir tais escolhas, é que efetivamente uma pessoa poderia buscar o autoconhecimento e a realização pessoal total. Por outro lado, não seria necessário reprimir a liberdade de expressão de um sujeito com tendências criminosas? São dois pontos de vista da relação/limite da liberdade de expressão e a realização pessoal.

Já a busca pela verdade, primeiro esbarra na dificuldade de se perceber se há ou não uma verdade. De qualquer forma, como a liberdade de expressão também protege falsas ideias e, muitas vezes, ideias inclusive prejudiciais à sociedade, tal argumento resta um pouco frágil para explicar a importância e a necessidade de proteção da liberdade de expressão.

b) A segunda hipótese é chamada autogoverno e estabilidade social ${ }^{10}$. Esta segunda hipótese traz a íntima relação da liberdade de expressão e a democracia. É importantíssimo, para que exista uma "democracia boa", que a sociedade esteja livre para criticar o governo e as decisões equivocadamente tomadas por este. A tolerância é muito mais eficiente para a manutenção do governo democrático do que a opressão, uma vez que da opressão podem surgir mártires e movimentos de oposição mais fortes e radicais, o que certamente geraria grande prejuízo ao sistema democrático.

Resumidamente analisadas as hipóteses acima, muitos são os estudiosos que entendem que essas hipóteses teóricas interessam muito mais a filosofia do que o direito, por serem de pouca aplicação prática (característica importante na realidade da common law). Além disso, a dificuldade em estabelecer quais os fundamentos que levaram à formação e evolução da proteção à liberdade de expressão torna inócua tal discussão, principalmente quando percebido que muitos são os valores atrelados a tal proteção, que vai muito além da democracia ou mesmo da realização pessoal através da liberdade de viver.

Assim, parece mais útil fazer uma análise histórica de como o instituto foi-se desenvolvendo, pensando não numa torre de valores, em que algum esteja no topo ou na fundação, mas sim numa teia de valores, na qual a liberdade de expressão é fio importante e condutor ${ }^{11}$.

\subsection{A História da Primeira Emenda}

Com a criação e desenvolvimento da imprensa escrita e da possibilidade de veiculação em massa de escritos, é que a censura iniciou seu papel mais relevante na história inglesa e norte-americana. Evidentemente, com a ampliação do acesso à informação, os ataques ao Estado se tornaram mais frequentes, o que gerou certa inquietude dos órgãos estatais, que, em muitos casos, censuraram certos discursos de oposição $0^{12}$.

\footnotetext{
${ }^{10}$ Ibidem, p. 05-07.

${ }^{11}$ FARBER, 2010, p. 06-08.

${ }^{12}$ Ibidem, p. 8-10.
} 
$\mathrm{Na}$ metade do século XVIII, na Inglaterra, seguida pelos Estados Unidos da América, é que se iniciou um movimento de liberdade de imprensa. Levando-se em consideração a evolução norte-americana, com o surgimento do Bill of Rights e das emendas à Constituição, como a Primeira Emenda, por exemplo, pode-se vislumbrar que houve momentos de repressão á imprensa (em prol de ideias estatais $x$ oposição) e outros momentos em que a liberdade de expressão tomou força e se sobressaiu. Porém, pelos poucos documentos deixados da época, difícil imaginar o que Madison $^{13}$, por exemplo, efetivamente quis dizer quando falava em liberdade de discurso e liberdade de imprensa.

O que se sabe, certamente, é que a Primeira Emenda surgiu como resposta ao medo de um controle central do Estado frente à população, principalmente em se tratando das minorias, como os escravos, que recentemente teria estabelecido sua liberdade com a Décima Quarta Emenda à Constituição Norte Americana.

\subsection{O Livre Discurso e a $14^{\mathrm{a}}$ Emenda}

A $14^{a}$ Emenda à Constituição dos EUA, para muitos historiadores (não há unanimidade no entendimento) trouxe uma maior importância à liberdade de expressão, assim como surgiu justamente para engrandecê-la, uma vez que a proibição de privar alguém de liberdade sem o devido processo legal, com uma interpretação extensiva, leva a crer que nenhum direito substantivo e essencial à liberdade (incluindo-se a de expressão) pode ser suprimido sem que haja um devido procedimento para tanto ${ }^{14}$.

Dessa forma, privar alguém de liberdade passou a ser matéria de extrema seriedade, pois deveria haver um processo democrático para tal restrição, englobando nesse contexto a liberdade de expressão, no sentido que sua privação não poderia ser prévia, mas sim sua ocorrência dependeria de um procedimento formal e constitucional.

\subsection{O Papel do Poder Judiciário na Evolução do Direito à} Liberdade de Expressão

Apesar de a Primeira Emenda ter sido promulgada em 1791, somente no início do século XX, principalmente com o estouro da $01^{\mathrm{a}}$ Guerra Mundial, é que passou a ser assunto mais corrente e debatido na Suprema Corte norte-americana.

A evolução da liberdade de expressão, no que se refere à interpretação judicial, pode ser posta em três momentos: num primeiro, o Estado a utiliza como base para retirar de circulação informações nocivas à sociedade; após, com a $01^{\mathrm{a}}$ Grande Guerra, houve um maior desenvolvimento de seu estudo e aplicação, o que veio a regredir com o estouro da Guerra Fria após a $02^{\mathrm{a}}$ Guerra Mundial (censura ao comunismo, visto como grande perigo).

\footnotetext{
13 Ibidem, p. 10.

14 Ibidem, p. 11.
}

DiREITOS Fundamentals $\varepsilon$ E JUSTIÇA - ANo 5, N 17, P. 325-346, OUt./DEZ. 2011 
Dos anos 1950 a 1960, viu-se uma maior proteção à liberdade de expressão. Já na chamada "era moderna", terceiro momento de evolução jurisprudencial no estudo e aplicação da Primeira Emenda, a jurisprudência passou a expandir sua aplicação, o que levou à criação de uma legislação de regras e princípios mais completa, sendo elencada a proteção à liberdade de expressão como uma das maiores responsabilidades das cortes norteamericanas, principalmente para a manutenção do Estado Democrático ${ }^{15}$.

Nessa linha de evolução é que se percebe o nascimento da ideia de existir um discurso menos protegido e um mais protegido, ideia que será desenvolvida nos tópicos seguintes ${ }^{16}$.

\section{A DEFINIÇÃO DA LIBERDADE DE EXPRESSÃO E SUA APLICAÇÃO}

Definir o conteúdo específico englobado pela liberdade de expressão é atualmente um dos grandes desafios da Suprema Corte norte-americana. Muitos são os casos em que o conteúdo do discurso é avaliado para ver se efetivamente deve ser protegido ou não pela Primeira Emenda. Há os conteúdos discriminatórios, neutros e também os pontos de vista que podem sofrer certa limitação das cortes de justiça norte americanas, o que pode levar a julgamentos contraditórios (um perigo na proteção da liberdade de expressão) ${ }^{17}$.

Intensa é a discussão aceca do tema. Alguns estudiosos e juízes pensam ser a melhor solução, no que se refere á proteção e aplicação da Primeira Emenda, deixar o regramento da matéria para o caso concreto, sem que se estabeleça o conteúdo específico que possa ser previamente censurado. Outros, por outro lado, entendem que regras devem existir, como no caso da proibição de discursos que incitem a raiva ou mesmo que tenham caráter discriminatório e racista. Não há unicidade na doutrina nem mesmo na jurisprudência da Suprema Corte.

Quando, no entanto, houver a intenção de analisar um caso em que haja restrição ou proteção à liberdade de expressão, alguns aspectos são obrigatórios para o real conhecimento da matéria. Primeiramente, o operador jurídico (seja advogado, promotor, juiz) deve entender que muito mais do que simplesmente resguardar o direito à expressão, a Primeira Emenda também resguarda a liberdade de se manter calado, de simplesmente não participar de eventos festivos do governo como, por exemplo, o thanksgiving (Ação de Graças) $^{18}$. Obrigar alguém a praticar qualquer ato que denote uma opção religiosa, racial, ou mesmo de posição política é também ofender a liberdade de expressão.

Além disso, importante referir que a expressão não está somente no discurso, ela também ocorre em atos, como já referido na questão da

\footnotetext{
${ }^{15}$ FARBER, 2010, p. 11-13.

16 Ibidem, p. 20-36.

17 Ibidem, p. 38-44.

${ }^{18}$ Ibidem, p. 38.
} 
queima da bandeira da nação norte-americana. A liberdade de expressão deve ser analisada de forma muita mais ampla que o mero discurso, passando pela possibilidade de queimar inclusive um crucifixo, por mais que tal ato venha a despertar a ira de religiosos praticantes. Outra questão a ser levantada é a proteção da liberdade ao silêncio, que se mostra tão importante quanto à proteção do ato ou do discurso em si ${ }^{19}$.

Por fim, outra ferramenta de extrema importância é analisar se (deve) existe uma espécie de censura prévia ao ato cometido ou se poderá haver alguma punição posterior ao discurso. Muitas são as críticas no sentido de existir um censura anterior ao ato ou discurso em si, frente à possibilidade de legislações se tornarem arbitrárias e inconstitucionais, até porque na grande maioria das vezes são legislações vagas (vagueza traz grande insegurança jurídica quanto à censura prévia, ampliando-a de forma perigosa). Deixar, por outro lado, o julgamento de discursos somente a cargo dos tribunais, pode levar a inconsistências e controvérsias ${ }^{20}$.

\subsection{O Discurso e suas Categorias}

Importante, antes de entrar na questão efetivamente do discurso de certas categorias ou classes, fazer um estudo da evolução da aplicação da Primeira Emenda nos EUA. Desde a Guerra Civil que levou os EUA a formarem o Estado Federativo atual, apesar da existência da Primeira Emenda, muitos eram os atos repressores por parte do Estado para com o discurso (principalmente da oposição). Salientam-se, como períodos mais opressores, os períodos das duas grandes Guerras Mundiais. O medo do comunismo e o advento da guerra fria fizeram com que a repressão ao discurso fosse muito forte, conforme já referido.

Muitos foram os célebres casos que chegaram às cortes norteamericanas ao longo dos períodos de guerra e de opressão, nos quais sujeitos eram condenados criminalmente por incitar modelos de governos distintos do democrático. A edição do Ato de $1798^{21}$, por exemplo, dizia que nenhuma informação agressiva, maliciosa ou escandalosa contra o governo estaria albergada na liberdade de expressão, realidade que atualmente não mais vigora.

Apenas a partir dos anos 1960 é que começou tanto na doutrina quanto na jurisprudência um cuidado maior com a liberdade de expressão, uma vez que movimentos pacíficos se intensificavam e mais, percebeu-se que muito mais do que reprimir os regimes autoritários era, preciso resguardar o diálogo para própria manutenção do regime democrático a duras penas defendido pelos norte-americanos ${ }^{22}$.

\footnotetext{
${ }^{19}$ FARBER, 2010, p. 40.

${ }^{20}$ Ibidem, p. 45.

${ }^{21}$ Ibidem, p. 57-59.

22 Ibidem, p. 57.
} 
A teoria que por muitos anos foi aplicada no sentido de "claro e presente perigo" ${ }^{\prime \prime}$, que justificava a censura prévia ou a posteriori no caso de oposição ao Estado, seria justificativa para a opressão e a censura de discurso, perdeu força a partir dos julgados de McCarthy ${ }^{24}$. Percebeu-se que simplesmente reprimir todos os discursos de formas e pensamentos distintos do Estatal era formar uma tirania que fazia perder força o ideal social-democrático. A segurança nacional já não é, na doutrina da liberdade de expressão atual, um argumento forte o bastante para a repressão do discurso. É preciso que haja efetivo discurso de raiva, racista e violento para que essa repressão de justifique ${ }^{25}$.

2.2. A Liberdade de Expressão (Imprensa) em Contraponto à Difamação e outros Prejuízos e Males

Continuando o estudo da evolução doutrinária e principalmente jurisprudencial (frente ao regime da common law vivenciado pela sociedade norte-americana), dando-se por ora destaque à questão de liberdade de imprensa, passa-se à análise do famoso caso Sullivan vs. New York Times ${ }^{26}$.

Sullivan exercia cargo de chefia na polícia na cidade de Montgomery. Ele ingressou com demanda indenizatória contra o jornal New York Times em razão de matéria feita pelo referido veículo de imprensa impressa, na qual eram noticiados abusos pela polícia da cidade de Montgomery. $\mathrm{Na}$ matéria, importante referir, não foi referido especificamente o nome de Sullivan, porém o mesmo alegou que pela leitura da matéria poder-se-ia perceber que os fatos levavam claramente à pessoa do requerente.

Nas instâncias inferiores, houve a condenação do jornal ao pagamento de indenização, uma vez que restou determinado que a notícia veiculada era difamatória e teria trazido danos ao policial. No entanto, na Suprema Corte, o debate se deu de outra forma.

Entendeu a Suprema Corte norte-americana que as figuras públicas oficiais não poderiam pleitear indenização por danos ocasionados por notícias difamatórias ou falsas veiculadas pela imprensa, a não ser que se comprove a má-fé na veiculação. Fala-se da má-fé quando a fonte que noticiou o fato sabia da falsidade da notícia ou não tomou os devidos cuidados para apurar sua veracidade.

Portanto, Sullivan, salvo se provasse que a fonte da matéria agiu sabendo que a notícia era difamatória ou falsa, ou que incorreu em espécie de negligência, não teria o direito ao recebimento de indenização. No caso, efetivamente veio o autor a ser vencido no pleito.

Criou-se, a partir desse caso, uma regra sobre a liberdade de imprensa, caso concreto que até hoje é paradigma.

\footnotetext{
${ }^{23}$ Ibidem, p. 58.

24 Ibidem, p. 63-66.

${ }^{25}$ Ibidem, p. 52-59 e 67-77.

${ }^{26}$ FARBER, 2010, p. 79-89.
} 
Os problemas na aplicação da regra acima referida, no entanto, são muitos: o que é pessoa pública oficial? O que é difamatório? O que é malicioso? Quando há má-fé?

A Suprema Corte não aplica a NYT rule (regra do caso Sullivan v. NYT ${ }^{27}$ em todos os casos de difamação, sendo que outras formas de julgamento também são utilizadas em casos em que a vítima da difamação ou da notícia maliciosa seja um mero particular e não pessoa pública.

Tratando-se de casos de liberdade de expressão de fatos de particulares, para que haja a proteção ao direito de discurso e expressão, importante se faz a análise da importância dos fatos e de seu conhecimento pelo público. Sendo de interesse público, o discurso deve ser protegido, sendo que somente em casos extremados é que deve sofrer alguma punição ou restrição.

Um caso interessante é o da divulgação do nome de uma vítima de estupro em jornal. A vítima passou a receber telefonemas e ameaças e teve que buscar proteção policial e acompanhamento psicológico. O jornal que noticiou o nome da vítima foi condenado em primeira instância ao pagamento de alta indenização, porém perante a Suprema Corte teve a condenação reformada, uma vez que os dados da vítima estavam publicados em documentos cedidos pela Polícia e o fato era de interesse público, caso de segurança pública. Nesse caso em particular, sobrepôs-se o valor social da informação para resguardo da liberdade de expressão, outro fundamento elaborado pela Suprema Corte, além dos trazidos pela regra do caso NYT ${ }^{28}$.

\subsection{Os Discursos de Ódio e a Linguagem Ofensiva}

Um assunto também importante para que se possa entender a extensão e a forma de aplicação da Primeira Emenda são os discursos de ódio e a linguagem ofensiva. O primeiro trata de discursos discriminatórios, ou que possam ensejar a violência de alguma forma. O segundo pode ser tratado como uma forma de linguagem que venha a incitar a violência ou mesmo que seja feita com o uso de palavras que não poderiam derivar de um discurso que promova o mínimo de interesse no público ${ }^{29}$.

Muitos são os casos que trataram as Cortes norte-americanas sobre 0 discurso com o uso de palavras ofensivas. Na grande maioria das vezes, o contexto em que proferido o discurso e as consequências que o mesmo veio a gerar é que efetivamente foram levados em consideração para a imposição de alguma espécie de sanção ou restrição à liberdade de expressão ${ }^{30}$.

O problema de sancionar ou não uma conduta pela sua potencialidade violenta é perigoso, pois não se pode prever que aquele discurso efetivamente levaria ou não a atos de violência.

\footnotetext{
${ }^{27}$ Ibidem, p. 85-89.

${ }^{28}$ Ibidem, p. 96-98.

${ }^{29}$ FARBER, 2010, p. 102-103.

30 Ibidem, p. 103-108.
} 
Outro aspecto que merece relevância é a questão do discurso racista ${ }^{31}$. A Primeira e a Décima Quarta emendas, em princípio, não apresentam qualquer conflito. No entanto, um país que busca, desde a abolição da escravatura, a inclusão dos negros à sociedade, na liberdade de expressão teria que, em alguns casos, também promover a sanção daqueles que no discurso demonstram algum tipo de racismo, o que em muitos julgados da Suprema Corte não foi examinado ou aplicado, sendo possível e muitas vezes protegido o discurso de cunho racial.

É uma discussão muito ampla, sendo que a doutrina acerca da Primeira Emenda parece ainda não ter conseguido elaborar teoria forte o suficiente para apresentar qualquer solução, sendo que caso a caso, salientando-se os casos em que universidades públicas figuram como entes que devem promover a inclusão racial, a liberdade de expressão deve ser vista também sob a ótica do discurso do ódio e o fomento às desigualdades raciais $^{32}$

\subsection{A Liberdade de Expressão e a Pornografia}

A pornografia é um item delicado quando se fala na liberdade de expressão. Muitos são os casos levados às Cortes norte-americanas que pretendem de alguma forma limitar a expressão sexual, havendo restrições quanto ao conteúdo, quanto às pessoas que podem ter acesso aos materiais supostamente pornográficos, além de saber o que efetivamente é pornográfico e o que não é (há dificuldade no limite entre o sexual e o pornográfico) $)^{33}$.

A limitação da pornografia na sociedade norte-americana pode ser explicada em termos históricos. Desde que havia a ideia de moralidade e de puritanismo (muito ligada às questões religiosas), é possível vislumbrar a aversão a espetáculos e materiais de cunho pornográfico pela sociedade norte-americana. No entanto, é importante ver se a pornografia está inserida nos conteúdos que fogem à proteção da liberdade de expressão (discurso menos protegido) trazida na Primeira Emenda (Justice Brennan's) ${ }^{34}$.

Como já referido anteriormente, os discursos de ódio ou mesmo os discursos com caráter racista podem ser excluídos da proteção pela liberdade de expressão em determinados casos, quando incitarem a violência ou utilizarem linguagem ofensiva. Porém, mesmo nesses casos, quando não restar comprovado o potencial dano à sociedade com o discurso (como a incitação à violência, por exemplo), o discurso não será reprimido, uma vez que não cabe ao Estado fazer a censura de conteúdos (Testes Roth e Two-Tier) ${ }^{35}$.

\footnotetext{
${ }^{31}$ Ibidem, p. 111-113.

32 Ibidem, p. 114-123.

33 Ibidem, p. 125-126.

${ }^{34}$ FARBER, 2010, p. 126.

${ }^{35}$ Ibidem, p. 128-130.
} 
A mesma regra deveria existir na liberdade de expressão quanto à pornografia, mas a pornografia e obscenidade são assuntos muito delicados, sendo que são dos mais diversos os moldes dos julgamentos proferidos pela Suprema Corte.

Muitos estudiosos têm como argumentação principal para limitação da liberdade de expressão na matéria o fato da pornografia incitar a violência, além de padrões equivocados de formas de vida.

Outros, no entanto, têm como objeto o zoneamento urbano ${ }^{36}$, sendo a matéria da pornografia debatida em razão do zoneamento especial (longe de bairros residenciais e de escolas) de cinemas cuja programação é adulta, sendo que haveria restrição da liberdade de expressão em alguns locais de determinada cidade.

A doutrina não tinha até pouco tempo atrás se detido ao estudo da matéria. Porém juntamente com os estudos de igualdade sexual e não discriminação da mulher, estudiosos têm se detido no tema da pornografia e os efeitos que ela pode trazer à sociedade.

Nesse contexto, novos julgamentos têm surgido ao restringir a expressão sexual, uma vez que a pornografia é vista como forma de incitar a violência contra a mulher e fazer com que a sociedade acredite numa subordinação das mulheres perante os homens, o que feriria o Bill of Rights norte-americano ${ }^{37}$.

No entanto, ainda não há um discurso uníssono quanto à matéria na doutrina ou na jurisprudência.

\subsection{A Liberdade de Expressão e a Atividade Empresarial}

Outro tipo de discurso que parece sofrer certa restrição quanto à proteção trazida pela Primeira Emenda é o discurso comercial, mais especificamente a propaganda. Até a metade da década de 1960, a propaganda comercial era excluída da proteção da liberdade de expressão, sendo que, chegando algum caso nas cortes norte-americanas, era tratada fora dos parâmetros da livre expressão ${ }^{38}$.

No entanto, com o caso Virginia State Boardof Pharmacy vs. Virginia Citizens Consumer Council Inc. ${ }^{39}$, a Suprema Corte incluiu definitivamente o ramo de propaganda na proteção da liberdade de expressão. No entanto, apesar da inclusão, até hoje o direito ao discurso empresarial é visto como uma segunda categoria (de segunda linha) de direitos assegurados pela Primeira Emenda, sofrendo, em alguns casos, restrições do Judiciário.

A análise da liberdade de expressão no ramo comercial passa por exame um pouco diferente dos demais ramos da liberdade de expressão.

\footnotetext{
${ }^{36}$ Ibidem, p. 134.

37 Ibidem, p. 139-146.

${ }^{38}$ Ibidem, p. 147-149.

${ }^{39}$ Ibidem, p. 149-150.
} 
Em razão do caráter quase que exclusivamente econômico da propaganda, acaba tendo menor força quando da busca pela liberdade plena de expressão, muitas vezes esbarrando em limitações baseadas na proteção ao consumidor e no interesse do Estado no produto ou serviço ${ }^{40}$.

Por exemplo, as propagandas de produtos nocivos, como cigarros e bebidas alcoólicas, sofrem e continuam sofrendo limitações por parte da legislação e da jurisprudência norte-americanas. Isso porque o interesse do Estado, muito além da liberdade de expressão, é de garantir a saúde de sua população. Para que haja a proteção do discurso comercial, o caso Central Hudson Gas v. Elec. Corp. .v Public Service Comm'n afirma, como uma espécie de paradigma para casos semelhantes, que a propaganda deve ser protegida se tiver como objeto produto ou serviço legal e de interesse social ${ }^{41}$.

Fazendo a análise das categorias de discursos que sofrem certa restrição (prévia e posterior), pode-se concluir que algumas formas de discurso recebem maior proteção e outras têm a proteção restringida em razão de seu caráter público, nocivo, etc.. A pornografia, a propaganda, o discurso racista ou de ódio, são alguns exemplos dos discursos que por um lado são protegidos pela Primeira Emenda, porém por outro sofrem da jurisprudência espécie de restrição, sendo considerados muitas vezes "não protegidos", pela abrangência da proteção ser reduzida (utilizando-se os critérios dos leading cases de cada matéria) ${ }^{42}$.

Portanto, a proteção à liberdade de expressão é forte, porém não ilimitada, podendo sofrer restrições em determinados casos, principalmente pela Jurisprudência.

\section{MATÉRIAS ESPECIAIS NO CONTEXTO DA LIBERDADE DE}

\section{EXPRESSÃO}

Além de fazer a análise da evolução da aplicação da Primeira Emenda, além de distinguir os discursos que possuem maior ou menor proteção, necessário analisar quais os locais onde o discurso e a liberdade de expressão podem ser vivenciados sem restrições (ou não).

\subsection{A Propriedade Pública}

O primeiro contexto a ser estudado quanto ao local para manifestação da liberdade de expressão é o da propriedade pública ${ }^{43}$. Em casos de liberdade de expressão examinados pela Suprema Corte, ruas, praças e calçadas parecem ser locais que, mesmo que públicos, e justamente por serem públicos, são locais de livre discurso.

Claro que falar de distinção entre a liberdade de expressão em um local particular e em um local público, no que se refira ao conteúdo do discurso,

\footnotetext{
${ }^{40}$ FARBER, 2010, p. 150-153.

41 Ibidem, p. 156-158.

${ }^{42}$ Ibidem, p. 162-165

${ }^{43}$ Ibidem, p. 167-173.
} 
parece inócuo, uma vez que as restrições, ou melhor, a quase plena liberdade é a mesma para os discursos ocorridos em locais privados ou locais de propriedade do Estado.

Mesmo assim, importante referir que, salvo calçadas, parques e ruas, locais em que há liberdade quase que total de manifestação, outras propriedades estatais podem sofrer alguma restrição no seu uso para a livre expressão $^{44}$.

Os Tribunais, por exemplo, são locais que podem sofrer restrição quanto à ocorrência de manifestações, uma vez que a ideia é que haja imparcialidade nos julgamentos, e movimentos e manifestações ocorridas no interior dos prédios das Cortes poderiam ferir e prejudicar a imparcialidade dos julgadores ${ }^{45}$.

Da mesma forma, uma universidade pública, que deve manter seus prédios e salas trancadas quando da não utilização, pode optar por permitir a reunião de alunos em suas dependências mesmo em horários após as aulas. No entanto, se permitir a entrada de alunos em horários extravagantes, deve permitir a entrada e o suo por todos os grupos que o quiserem, seja de cunho recreativo, seja de cunho religioso dentre outros ${ }^{46}$.

Outro aspecto interessante estudado é a questão de existir a necessidade de obtenção de licenças ${ }^{47}$ para que seja permitida a ocorrência de certos eventos, mesmo que em locais públicos como ruas e praças. A jurisprudência é clara no sentido de que o Estado poderá exigir licenças para eventos que contem com um grupo maior de pessoas, como passeatas ou shows, porém a licença é no sentido de preparação do Estado para com seu aparato policial e de trânsito, jamais fazendo censura do conteúdo da manifestação a ser realizada ${ }^{48}$.

O local, o horário e a forma do discurso são passíveis de análise pelo Judiciário, sendo possível a restrição a um horário (respeito ao horário de silêncio), local (perto de escolas pode prejudicar o estudo) ou a forma (passeatas no meio do trânsito sem licença ou auxílio da polícia).

Portanto, além de sofrer restrição quanto ao conteúdo, a liberdade de expressão pode também sofrer restrição em decorrência do local, horário e forma a que venha ocorrer.

\subsection{Sujeitos que sofrem Restrição à Liberdade de Expressão}

Além do Estado poder restringir local e horário (e até mesmo conteúdo em casos específicos), para alguns sujeitos essa restrição é ainda maior ${ }^{49}$.

\footnotetext{
${ }^{44}$ Ibidem, p. 169.

${ }^{45}$ FARBER, 2010, p. 169-171.

${ }^{46}$ Ibidem, p. 171.

47 Ibidem, p. 177-180.

48 Ibidem, p. 175-177.

49 Ibidem, p. 187.
} 


\subsubsection{Sujeitos que sofrem restrição}

Os estudantes de escolas públicas, por exemplo, pela imaturidade, podem sofrer certa censura por parte dos professores e demais integrantes do corpo escolar. Porém tal censura deve ser bem equacionada, pois os abusos têm sido afastados pela Suprema Corte norte-americana ${ }^{50}$.

Os presos também são sujeitos que, mesmo tendo maturidade, pelo seu histórico criminoso, sofrem restrições, como as revistas que terão acesso (pode haver inflamação à revolta ou violência), ou mesmo os tipos de correspondências que poderão receber ${ }^{51}$.

Mas o sujeito que mais possui seu direito de expressão e discurso limitado é o militar. Isso porque tanto está sob custódia do Estado como também é funcionário dele ${ }^{52}$.

O funcionário público ${ }^{53}$, na sua vida particular, tem acesso a qualquer informação, porém na sua atividade e dentro dos interesses do órgão que representa deve manter respeito às instituições, sendo resguardado 0 discurso que não fira diretamente suas funções exercidas. Portanto, o funcionário público tem sim limitação quanto à liberdade de expressão, uma vez que representa e está empregado pelo Poder Público.

O militar, além da restrição do funcionário público, como já referido está sob a custódia do Estado, num regime de disciplina tal que não permite uma liberdade de expressão nos moldes da população em geral.

\subsubsection{Das restrições aos fundos e patrocínios}

Outro aspecto referente à forma de repressão da liberdade de expressão pelo Estado é a restrição de patrocínios e distribuição de subsídios ${ }^{54}$. O Estado pode distribuir fundos para que haja campanha no que se refere ao planejamento familiar, porém restringir a possibilidade de divulgação de incentivo ao aborto como forma de planejamento familiar.

É tênue a condicionalidade imposta pelo Estado para distribuição de fundos a campanhas em relação à limitação à liberdade de expressão, sendo importante, no caso concreto, ver se a condição imposta é razoável e admite a exceção à liberdade de discurso.

Importante é que não se perca de vista a ideia de que uma censura prévia deve ser evitada, até mesmo para que não haja ameaça à democracia, principalmente quando o caos envolver recursos públicos de financiamento ${ }^{55}$.

\footnotetext{
${ }^{50}$ Ibidem, p. 187-190.

${ }^{51}$ Ibidem, p. 191-192.

52 Ibidem, p. 192-193.

${ }^{53}$ Ibidem, p. 193-199.

${ }^{54}$ FARBER, 2010, p. 199-204.

${ }^{5}$ Ibidem, p. 204.
} 


\subsection{A Mídia e a Liberdade de Expressão}

Dentro do panorama da Primeira Emenda, a mídia tem grande papel em seu estudo. Não é a toa que a liberdade de expressão e a liberdade de imprensa aparecem distintamente na redação do texto estudado, sendo a liberdade de da mídia uma liberdade, pode-se dizer, mas responsabilizável ${ }^{56}$.

\subsubsection{A mídia e o acesso à informação}

O primeiro aspecto a ser analisado é o acesso da mídia a informações sobre casos judiciais e policiais e seu papel em julgamentos, principalmente de casos criminosos.

Sabe-se que muitas são as fontes da mídia, sendo que todo jornal ou canal de televisão possui fontes "anônimas" que repassam as informações ao veículo que, por consequência, divulga o mesmo para a população em geral. Dessa forma, muitas vezes a "mídia" é chamada a depor em julgamentos, sendo que há controvérsia na jurisprudência da suprema corte no sentido de proteger as fontes ou exigir, pelo interesse social, do repórter a prestação de informações dadas em sigilo ${ }^{57}$.

Da mesma forma, a publicidade acerca de um caso pode ser determinante num julgamento. O caso do $D r$. Sheppard, que levou à produção do filme O Fugitivo é um exemplo. O réu foi a julgamento quase que previamente condenado, frente à ampla e irrestrita informação que a mídia já havia passado sobre o caso antes mesmo da formação do corpo de jurados. Mas há resguardo pela legislação e jurisprudência da informação a ser passada pela mídia e sua liberdade de expressão, sendo a construção de julgados que restrinjam tal divulgação corrente nos dias atuais (principalmente pela rapidez da informação) ${ }^{58}$.

Importante ressalvar a questão do advogado que atua na causa que, ao contrário dos demais cidadãos, por ser um agente de Justiça assim como o juiz e o promotor, tem maior responsabilidade quanto aos dados que deixa vazar na imprensa sobre um caso determinado em que atua, estando sua liberdade de expressão restrita à estratégia de defesa. Caso ultrapasse tal limite, o advogado pode ser severamente responsabilizado ${ }^{59}$.

Outro assunto bastante debatido na questão da liberdade de expressão e a mídia é o acesso às informações em poder do Estado pela imprensa.

A jurisprudência, nesse assunto, é dividia, no sentido de entender se a mídia, além do cidadão comum, teria alguma prerrogativa na obtenção de informações em posse do Estado, vendo como exemplos a questão de documentos de processos judiciais, visitas a prisões assim como entrevistas com prisioneiros ou mesmo funcionários públicos ${ }^{60}$.

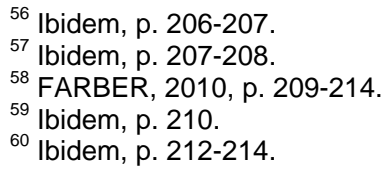




\subsubsection{A imprensa escrita e a imprensa falada}

Uma diferenciação de entendimento tanto jurisprudencial quanto doutrinário no que se refere à imprensa é a diferença de liberdade de proteção da imprensa escrita e da falada (rádios e televisões). A escrita (impressa) tem quase liberdade total e proteção total pela Primeira Emenda, sendo aplicado o caso paradigma do New York Times já comentado. Já a televisão e a rádio sofrem restrições inclusive quanto à possibilidade de receber do governo a licença para seu funcionamento (órgão é FCC), havendo discricionariedade ao órgão que concede a licença ver a diversidade das emissoras e não permitir que haja monopólio da informação a um mesmo grupo ${ }^{61}$.

Uma nova preocupação também hoje movimenta a doutrina e jurisprudência são as novas tecnologias, mais precisamente a internet. A rapidez da informação, além de ser informação falada, escrita, "impressa", faz com que as Cortes se dividam em aplicar a liberdade quase que irrestrita na mídia impressa ou as regulações (inclusive prévias) da mídia de imagem e som.

Enfim, muito ainda a ser discutido. Por um lado, os republicanos, amparados por ideias trazidas por John Locke $^{62}$ entendem que há necessidade de regulação pelo Estado no sentido de permitir que haja acesso a todo tipo de informação à sociedade, entendendo que cabe ao Estado fazer com que a informação chegue à população em geral, o que denota que deve haver certa ingerência estatal também no âmbito da internet. Já outros grupos entendem desnecessária a atuação do estado na divulgação da informação pela mídia, entendendo que contar com o "bom senso" do Estado quando da elaboração de uma norma de restrição seria perigoso ${ }^{63}$.

\subsection{A Liberdade de Associação}

A liberdade de associação também é matéria discutida nos moldes da aplicação da Primeira Emenda. $O$ final do texto da primeira emenda fala claramente na liberdade de associação, sendo tal direito em diversas formas protegido com o uso da prerrogativa de liberdade de expressão ${ }^{64}$.

\subsubsection{A liberdade de associação e a discriminação}

Quando se trata de um grupo particular, pouca influência tem o Estado na organização de grupos, estando tais casos, na maioria das vezes, ligados a questões de discriminação. Um exemplo é o caso Roberts $v$. United States Jaycees $^{65}$, no qual foi intentada uma ação frente à proibição de associação de mulheres a determinado grupo. Nesse caso, a Suprema Corte entendeu

\footnotetext{
${ }^{61}$ Ibidem, p. 214-218.

62 Ibidem, p. 219-220.

63 Ibidem, p. 222-223.

${ }^{64}$ FARBER, 2010, p. 224-225.

65 Ibidem, p. 225-226.
} 
que os propósitos do grupo não seriam afetados com o ingresso de mulheres, sendo descabida e fora do interesse do Estado a manutenção do estado de discriminação colocado.

Já no caso Boy Scouts of America v. Dale ${ }^{66}$ foi levado caso à Suprema Corte frente à expulsão de um escoteiro homossexual de um grupo de escoteiros. A Corte, neste caso, entendeu que a vontade do grupo deveria prevalecer, uma vez que a aceitação de um membro homossexual feriria os ideais da associação em si, da mesma forma que no caso Hurley v. Irishamerican Gay, lesbian, and Bisexual Group ${ }^{67}$.

\subsubsection{A liberdade de expressão e as eleições}

Outro aspecto levantado sobre a influência do Estado na liberdade de associação, relacionada à liberdade de expressão, é a possibilidade de levantamento de fundos para as eleições ${ }^{68}$. Entende a Suprema Corte norte-americana que financiar uma campanha é forma de liberdade de expressão, fazendo análise do federal Election Campaign Act of $1974^{69}$, série de regramentos referentes ao levantamento de fundos criados após o escândalo de Watergate.

O referido ato normativo trouxe diversos limites para o levantamento de fundos em campanhas eleitorais, assim como para despesas e contribuições. Como referido que a Corte entende o gasto com campanhas forma de liberdade de expressão, criou algumas normas sobre a aplicação ou não das restrições no levantamento de fundos em campanhas, podendo tais normas ser resumidas da seguinte forma: as despesas com campanhas não devem sofrer limitações, porém as contribuição individuais, assim como (e principalmente) a de empresas e grupos corporativos, devem ser limitadas para evitar a corrupção ${ }^{70}$.

Muita controvérsia corre na discussão acima entabulada, principalmente quanto à dificuldade que a arrecadação de fundos como normatizado pode gerar uma menor informação acerca de determinado candidato e suas ideias ao grande público. Certamente ainda muito debate será feito nessa matéria.

Assim pode-se concluir que, quando a liberdade de expressão sai do âmbito particular e passa a análise de expressão pública (funcionários, prisioneiros, partidos políticos) ou quase-públicos (a mídia, por exemplo), sofre maiores restrições, restrições essas de caráter jurisprudencial e legislativo, o que pode ser considerado espécie de censura prévia à liberdade de expressão ${ }^{71}$.

${ }^{66}$ Ibidem, p. 227-228.

${ }^{67}$ Ibidem, p. 226-227.

${ }^{68}$ Ibidem, p. 231-232.

${ }^{69}$ Ibidem, p. 234-237.

${ }^{70}$ Ibidem, p. 240-242.

${ }^{71}$ FARBER, 2010, p. 242-243. 


\section{A LIBERDADE DE EXPRESSÃO E A LIBERDADE RELIGIOSA}

A liberdade religiosa é outra vertente importante de estudo quando analisada a Primeira Emenda à Constituição norte-americana.

\subsection{A Evolução Histórica}

A primeira base para que seja respondida a pergunta de por que a religião deve receber uma proteção especial pelo Estado pode ser estabelecida em termos históricos. Desde que na Dinastia Tudor houve a ocorrência de guerras frente ao catolicismo romano e o protestantismo inglês, percebeu-se e posteriormente principalmente por Locke, que a atuação do Estado deveria estar separada da religião, até mesmo para que se pudesse resguardar a paz entre pessoas do mesmo povo, porém com credos distintos $^{72}$. Os presidentes Jefferson e após Madison levaram tal concepção ao poder legislativo, que acabou por enumerar como cláusula aberta da Primeira Emenda a liberdade de religião ${ }^{73}$.

A religião recebeu grande atributo de proteção, sendo que a doutrina que estuda a extensão e a aplicação da primeira emenda pergunta-se por qual razão a religião tem essa proteção toda, e qual seria o interesse do estado em garantir com tamanha força tal liberdade e desvinculação? Três são as respostas hoje enumeradas pela doutrina norte-americana.

A primeira, iniciada pelo já citado filósofo Locke e mais atualmente defendidas por John Rawls e Ronald Dworkin fala na limitação do poder do Estado, o qual existe única e exclusivamente para garantir aos particulares a possibilidade e os meios para perseguirem seus próprios ideais de vida, sendo a liberdade e diversidade de religião é clara autonomia que o particular deve ter na ideia liberal da atualidade ${ }^{74}$.

Uma segunda perspectiva para explicar o importante papel da liberdade de religião na sociedade é defendida por Madison, o qual afirma que a diversidade de religiões fará com que uma infinidade de grupos sejam formados, sendo que tal pulverização de visões de mundo virá a oprimir a formação de um grupo hegemônico no poder, inibindo eventual autoritarismo ou tirania ${ }^{75}$.

A terceira resposta à pergunta acima referida é que a religião tem um quê de loucura, de insensatez e, nesse contexto, assim como são feitas concessões a loucos de todo gênero, tais concessões e liberdades devem também ser aplicadas à religião ${ }^{76}$.

De qualquer forma, seja qual for a razão para a proteção da liberdade de culto e a liberdade de exercício de religião, muitos são os casos levados à Corte norte-americana buscando proteção a esse exercício.

\footnotetext{
72 Ibidem, p. 246-247

73 Ibidem, p. 247.

74 Ibidem, p. 248.

${ }^{75}$ Ibidem, p. 248-249.

${ }^{76}$ Ibidem, p. 249.
} 
4.2. A Liberdade Religiosa, a Liberdade de Expressão e a Jurisprudência

Um primeiro caso que merece análise quanto aos julgamentos da Suprema Corte norte-americana trata de uma funcionária que acabou por perder o emprego e outras oportunidades de se colocar no mercado frente à sua religião não permitir o exercício de trabalho aos sábados (Sherbert v. Verner $)^{77}$.

O seu direito de receber benefícios pelos sábados, mesmo sem efetivo trabalho, foi garantido pelo Judiciário frente à cláusula de liberdade religiosa. Em outro caso, um sujeito havia sido condenado por não matricular seu filho na escola, sendo que restavam ao menos dois anos para conclusão dos estudos, o que era obrigatório na localidade onde residia a família ${ }^{78}$. Ocorre que a religião do sujeito (Amish - judeus ortodoxos) pregava que a educação deveria ser completada pela comunidade, inexistindo a necessidade de frequentar a escola por mais dois anos. Nos dois casos, entendeu a Corte por assegurar aos sujeitos a liberdade de exercício religioso, mesmo que tal exercício possa violar outras normas trazidas pelo sistema legislativo. Essa posição é defendida pelo caso paradigma Sherbert $v$. Verner, acima referido.

Por outro lado, em caso paradigma Employment Divison v. Smith, dois funcionários foram demitidos e tiveram espécie de seguro-desemprego negado, uma vez que a demissão se deu por justa causa frente à constatação de que, em ritual religioso, haviam se entorpecido com a planta chamada Peiote. A corte, neste caso, ao invés de resguardar o exercício religioso, frente à criminalização da conduta, abriu precedente no sentido de que o exercício da religião não pode ser utilizado como desculpa para a prática de atos criminosos. Deve haver, no caso concreto, a análise e o sopesamento do direito constitucional do exercício religioso e outro bem constitucional igualmente abrigado na carta maior ${ }^{79}$.

O caso Smith (e o paradigma formado em torno dele) até hoje é utilizado, sendo que rende muitos debates sobre a possibilidade de opressão, por parte do estado, do exercício de religião. Eis um assunto que está longe de ser resolvido ${ }^{80}$.

\subsection{O Livre Exercício de Religião}

Impossível tratar da liberdade de expressão e liberdade religiosa sem que se faça a análise da Estableshment Clause, que está ligada à Primeira Emenda, a qual traz espécie de cláusula pétrea no sentido de que o Estado não pode optar por uma religião oficialmente, não pode promover nenhum tipo de religião, assim como deve proteger o livre exercício religioso ${ }^{81}$.

\footnotetext{
${ }^{77}$ FARBER, 2010, p. 251-254.

${ }^{78}$ Ibidem, p. 252.

79 Ibidem, p. 254-258.

80 Ibidem, p. 259-264.

${ }^{81}$ Ibidem, p. 266.
} 
No entanto, a história da referida cláusula não é de todo pacífica, sendo que sua interpretação nos Tribunais, assim como pela própria atuação estatal (executiva), é controvertida e oscila em diversas linhas de opinião.

Uma primeira linha de pensamento entende ser absolutamente imprescindível que o Estado em nada se relacione com a religião, deixando a cargo dos particulares escolherem e fomentar suas crenças. Nesse contexto, muitas foram as leis e normas declaradas inconstitucionais, pois faziam esta relação Estado-religião. Um exemplo ocorreu na Virginia, onde havia legislação que proibia qualquer pessoa que não acreditasse na divina trindade de exercer cargos públicos, podendo inclusive ser privado de propriedade por tal razão. Tomas Jefferson criticou de forma categórica tal legislação, trazendo justamente a ideia de que o estado deve estar separado da religião, até mesmo para a manutenção da paz social ${ }^{82}$.

Em outros momentos, era permitida a influência do Estado em questões religiosas, como, por exemplo, a manutenção de calendário com feriados de cunho absolutamente religioso ${ }^{83}$.

A doutrina, frente ao contexto multifacetário vivenciado no estudo e aplicação da cláusula de estabelecimento frente à liberdade de exercício de religião, evoluiu no sentido de perceber que a Suprema Corte, assim como o próprio poder legislativo norte-americano em alguns casos deveria permitir, por exemplo, o ingresso de professores públicos em escolas com cunho religioso determinado para auxiliar na educação, porém em outros percebe que dividir fundos das escolas públicas com escolas paroquiais feriria tanto a neutralidade do Estado como as próprias escolas e suas religiões perderiam autonomia na pregação de suas crenças ${ }^{84}$.

Há duas linhas doutrinárias que podem ser destacadas, sendo a primeira formada pelos separatistas, que entendem ser vital a absoluta e irrestrita separação do Estado e da Religião, e os mais moderados, que entendem que o Estado não só deve permitir o exercício da religião, mas também deve intervir para que esse exercício seja possível, por exemplo, ajudando no financiamento de escolas com cunho religioso definido ${ }^{85}$.

Tal discussão é matéria de inúmeras obras atuais sobre a primeira Emenda, havendo dificuldade no encontro de posição dominante. Clause

4.4. A Dificuldade da Jurisprudência na Aplicação da Estableshment

Muitas são as técnicas utilizadas pelos Juízes norte-americanos para que haja a total eficácia da cláusula de livre exercício de religião nos Estados Unidos. Alguns testes foram aplicados nos casos concretos, sendo

\footnotetext{
${ }^{82}$ FARBER, 2010, p. 266-269.

${ }^{83}$ Ibidem, p. 267.

${ }^{84}$ Ibidem, p. 271-272.

${ }^{85}$ Ibidem, p. 271-272.
} 
o primeiro o teste Lemon, pregando a total dissociação do estado e da religião, após o teste feito pela juíza O'Connor, usando como base a premissa de que todos são iguais perante a lei, independentemente de sua religião, dentre outras formas como o uso da coerção como base para julgamentos $^{86}$.

No entanto, cada uma das técnicas utilizadas para a solução de conflitos envolvendo a liberdade de exercício de religião e sua dissociação com o Estado contem problemas, sendo difícil encontrar uma unicidade quanto aos julgados e interpretações.

Um grande problema enfrentado pela Suprema Corte norte-americana diz respeito às escolas públicas e as escolas paroquiais (com religião estabelecida). Muitos são os casos levados ao Judiciário nos quais se discute a possibilidade de escolas paroquiais receberem fundos do Estado, ou mesmo escolas públicas receberem o auxilio de profissionais de escolas paroquiais ou mesmo abrir suas portas para programas religiosos fora do horário escolar ${ }^{87}$.

Não há um discurso único e coerente nos julgados de casos com os acima referidos. Ora a Suprema Corte entende haver o desrespeito á regra de que o Estado não deve optar ou financiar uma religião. Em outros, como no caso de permitir que as escolas mantenham sala disponível para que seja feito espécie de grupo de estudo sobre a bíblia, entende a Corte que não há ferimento ao estabelecido na cláusula de liberdade de exercício religioso.

Enfim, a controvérsia passa não só na legislação, mas na própria formação da Suprema Corte, sendo que ora a juíza O'Conner vota utilizando suas ideias e testes, ora é vencedor o voto do Juiz Scalia, que entende que o discurso religioso particular não feriria a cláusula estudada ${ }^{88}$. Não há, portanto, consenso ou mesmo um direção majoritária na solução dos conflitos envolvendo a liberdade de exercício religioso, principalmente no âmbito das escolas públicas.

4.5. As Possíveis Soluções aos Problemas da Liberdade de Exercício de Religião

Três são as hipóteses de solução trazidas por Farber após a análise dos impasses enfrentados pela Suprema Corte norte-americana na matéria. Foca-se em três soluções que podem ser utilizadas.

A primeira delas fala de um extremo, no qual a ideia base é que o Estado jamais deve se envolver com a religião, seja a favor ou contra a mesma, não podendo sequer acomodar e manter ambiente propício ao exercício religioso, baseado na ideia de secularismo ${ }^{89}$.

\footnotetext{
${ }^{86}$ Ibidem, p. $273-276$

${ }^{87}$ Ibidem, p. 276-282.

${ }^{88}$ FARBER, 2010, p. 281.

${ }^{89}$ Ibidem, p. 284.
} 
A segunda hipótese seria a do pluralismo, na qual a liberdade de exercício existe para criar um ambiente propício à formação de uma sociedade de diversas religiões, um mundo de diversidades. Há separação entre Estado e religião, porém o primeiro deve manter e propiciar ambiente que promova a diversidade ${ }^{90}$.

A terceira e última hipótese é a da maioria, na qual se estabelece que constitucionalmente não há dever do estado de promover a acomodação da diversidade religiosa, sendo que a religião, na discricionariedade do estado, poderá receber incentivos ${ }^{91}$.

Não há, no entanto, uma resposta única às questões levantadas quando se estabelece a relação entre Estado e religião, na ótica da Primeira a Emenda e, principalmente, da liberdade de exercício religioso, sendo ainda campo vasto de discussão e discórdia ${ }^{92}$.

\section{CONSIDERAÇÕES FINAIS}

Após análise da Primeira Emenda Constitucional norte-americana, que não tentou em momento algum ser exaustiva, a qual trata da liberdade de expressão, percebe-se que há grande campo de trabalho ao jurista na matéria levantada, pois alguns são os consensos sobre sua aplicação, e muitas são as discussões que ainda são levadas ao Judiciário.

De qualquer forma, na evolução histórica da aplicação da Primeira Emenda percebe-se, nos últimos quarenta anos, que o Estado não mais pode censurar ideias e discursos contrários a seus ideais, sendo tal liberdade resguardada. Mesmo o mais polêmico dos discursos, desde que não caia nos conteúdos de restrição mínima da liberdade de expressão, estará seguro constitucionalmente.

O que interessa é que, no século XXI, pode-se dizer que o mais intangível dos direitos de liberdade já é conhecido: o direito de liberdade de expressão e discurso ${ }^{93}$.

\section{REFERÊNCIAS BIBLIOGRÁFICAS}

DAVID, René. Os Grandes Sistemas do Direito Contemporâneo. 4. ed., São Paulo: Martins Fontes, 2002.

FARBER, Daniel A. The First Amendment. New York: Thomson Reuters, 2010.

\footnotetext{
90 Ibidem, p. 284.

91 Ibidem, p. 284-285.

92 Ibidem, p. 286-287.

${ }^{93}$ FARBER, 2010, p. 287.
} 